\title{
ABO Gene Polymorphism and Thrombomodulin -33G $>$ A Polymorphism Were Not Risk Factors for Myocardial Infarction in Javanese Men
}

\author{
Mifetika Lukitasari, ${ }^{1}$ Ahmad Hamim Sadewa, ${ }^{2}$ and Mohammad Saifur Rohman ${ }^{3}$ \\ ${ }^{1}$ Department of Nursing, Faculty of Medicine, Brawijaya University, Malang, Indonesia \\ ${ }^{2}$ Faculty of Medicine, Gadjah Mada University, Yogyakarta, Indonesia \\ ${ }^{3}$ Department of Cardiology and Vascular Medicine, Faculty of Medicine, Brawijaya University, Malang, Indonesia \\ Correspondence should be addressed to Mohammad Saifur Rohman; ippoenk@yahoo.com
}

Received 21 February 2017; Revised 30 May 2017; Accepted 6 June 2017; Published 24 July 2017

Academic Editor: Bhagwan Satiani

Copyright (C) 2017 Mifetika Lukitasari et al. This is an open access article distributed under the Creative Commons Attribution License, which permits unrestricted use, distribution, and reproduction in any medium, provided the original work is properly cited.

\begin{abstract}
Genetic factors contribute to about a half of coronary artery diseases. During the last several decades, some studies suggested that non-O blood group and thrombomodulin polymorphism -33G $>$ A are the risk factors of coronary artery disease especially in Asia. There was no prior study in Indonesia regarding this issue. Hence, this study was designed to investigate the correlation of $\mathrm{ABO}$ polymorphism and thrombomodulin polymorphism -33G $>$ A with the incidence of acute myocardial infarction (AMI). A total of 192 subjects were enrolled in this case control study. AMI patients were diagnosed based on World Health Organization criteria. Healthy patients were subjects with AMI risk factor without any sign and symptoms of AMI. Patients with diabetes mellitus, cancer, and arrhythmia were excluded from this study. Genotyping for both polymorphisms was performed by PCR RFLP methods. The result of this study suggested that $\mathrm{ABO}$ polymorphism and thrombomodulin polymorphism $-33 \mathrm{G}>\mathrm{A}$ were not risk factors of $\mathrm{AMI}$, $p=0.727$ and $p=0.699$, respectively. Furthermore, the analysis to identify the synergy of these polymorphisms failed to prove their correlation with AMI $(p=0.118)$. Conclusively, this study showed that ABO polymorphism and thrombomodulin polymorphism $-33 \mathrm{G}>\mathrm{A}$ were not risk factors of AMI.
\end{abstract}

\section{Introduction}

Coronary artery disease is the leading cause of death and disability in the world [1]. Acute myocardial infarction (AMI) is the most serious clinical manifestation of coronary artery disease leading to irreversible heart necrosis due to prolonged ischemia [2]. Genetic factors contribute to about a half of coronary artery diseases [3].

During the last several decades, some studies suggested that non-O blood group was a risk factor of myocardial infarction. Previous study on Caucasians revealed that blood group was a determinant of myocardial infarction susceptibility [4]. There is no prior study in Indonesia regarding this issue. This issue was explained by modulation of vonWillebrand Factor (vWF) by A and B glycosyltransferase [5].
Moreover, non-O blood group has 25\% higher level of vWF compared to that of O blood group [6].

Thrombomodulin polymorphism $-33 \mathrm{G}>\mathrm{A}$ was reported as a determinant of myocardial infarction susceptibility in Asia [7-9]. Thrombomodulin gene produces thrombomodulin as a receptor in endothelial cell surface area and makes a complex with thrombin. This complex activates $\mathrm{C}$ protein that cleaves factor V and factor VIII. Thrombin-thrombomodulin complex will lose all of its procoagulant activity [10]. Polymorphism in the promoter region of this gene will lead to the decline of thrombomodulin gene expression $[8,11]$.

In Indonesia, we have no data regarding those issues; ethnic differences may contribute to this fact. Hence, this study was designed to investigate the correlation of $\mathrm{ABO}$ polymorphism and thrombomodulin polymorphism $-33 \mathrm{G}>\mathrm{A}$ with 
TABLE 1: Primer in ABO polymorphism identification.

\begin{tabular}{ccc}
\hline Primer & Sequence $\left(5^{\prime}-3^{\prime}\right)$ & Name \\
\hline ABO-1 & GCAGTAGGAAGGATGTCCTC & A7500 (261F) \\
ABO-2 & AATGTCCACAGTCACTCGCC & A7501 (261R) \\
ABO-3 & TGGAGATCCTGACTCCGCTG & A7502 (703F) \\
ABO-4 & GTAGAAATCGCCCTCGTCCTT & A7503 (703R) \\
\hline
\end{tabular}

the incidence of acute myocardial infarction in Javanese men.

\section{Patients and Method}

2.1. Patients. A case control study was conducted in a total of one hundred and ninety-two subjects. Myocardial infarction was diagnosed by cardiologists based on World Health Organization criteria, that is, the manifestation of any 2 of the following 3 criteria: cardiac chest pain, electrocardiography changes in 2 consecutive leads that showed ST elevation or ST depression, and troponin I level increase in 4 hours after onset. Moreover, control subjects were patients with myocardial infarction risk factors such as smoking, hypertension, and dyslipidemia. Mostly, the control group was obtained from hypertensive community patients. Patients with diabetes mellitus, vascular disease, cancer, and arrhythmia were excluded from this study. This study excluded patients with diabetes mellitus and vascular disease since $\mathrm{ABO}$ gene and thrombomodulin $-33 \mathrm{G}>\mathrm{A}$ polymorphism were polymorphism in thrombotic pathway and diabetes mellitus and vascular disease significantly enhanced the thrombotic event that consequently enhances the acute myocardial infarction risk.

2.2. Methods. Thrombomodulin $-33 \mathrm{G}>\mathrm{A}$ polymorphism was identified by PCR RFLP method. The primers were forward: $5^{\prime}$-GGCCAGGGCTCGAGTTTATAAAGGC-3' and reverse: $5^{\prime}$-CGGGGACAGTCGTCTTGTTACAGG-3' ${ }^{\prime}$. Furthermore, the $259 \mathrm{bp}$ PCR product was digested by Stu I enzyme and electrophoresed in 3\% agarose gel. GG genotype resulted in $235 \mathrm{bp}$, AG genotype $235 \mathrm{bp}$ and $24 \mathrm{bp}$, and AA genotype $235 \mathrm{bp}$ [10].

$\mathrm{ABO}$ polymorphism was identified by PCR RFLP method with the primers shown in Table 1. Furthermore, the PCR product was digested by Kpn and Alu I enzyme and electrophoresed in 3\% agarose gel. The RFLP result was interpreted based on the previous research [12].

2.3. Statistical Analysis. The data were analyzed by chi-square test. Difference was found to be significant if $p<0.05$.

2.4. Ethical Considerations. The study obtained ethical clearance from Medical and Health Research Ethics Committee (MHREC), Faculty of Medicine, Gadjah Mada University, Dr. Sardjito General Hospital. The informed consent was obtained prior to study enrollment.
TABLE 2: Baseline characteristics.

\begin{tabular}{lccc}
\hline Variables & Case $(n=99)$ & Control $(n=93)$ & $p$ \\
\hline Age & $56,45 \pm 9,70$ & $56,19 \pm 9,79$ & $0,853^{*}$ \\
BMI $\left(\mathrm{kg} / \mathrm{m}^{2}\right)$ & & & \\
Normal $(18.25$ to $<25)$ & $39(39,4)$ & $23(24,7)$ & $0,004^{\#}$ \\
Overweight $(25$ to $<30)$ & $24(24,2)$ & $18(19,4)$ & \\
Obese 1 $(30$ to $<35)$ & $26(26,3)$ & $42(45,2)$ & \\
Obese 2 $(35$ to $<40)$ & $6(6,1)$ & $10(10,8)$ & \\
Dyslipidemia (yes) & $39(39,4)$ & $40(43)$ & $0,717^{\#}$ \\
Smoking (yes) & $81(81,8)$ & $42(45,2)$ & $0,000^{\#}$ \\
HT (yes) & $42(42,4)$ & $83(89,2)$ & $0,000^{\#}$ \\
\hline
\end{tabular}

Data is represented in $n$ (\%). ${ }^{*}$ Data were analyzed by independent $t$-test.

${ }^{\#}$ Data were analyzed by chi-square test. BMI: body mass index.

TABLE 3: Association between ABO gene polymorphism $-33 \mathrm{G}>\mathrm{A}$ and acute myocardial infarct based on blood groups $\mathrm{O}$ and non-O.

\begin{tabular}{lccccc}
\hline Variables & $\begin{array}{c}\text { Cases } \\
(n=99)\end{array}$ & $\begin{array}{c}\text { Control } \\
(n=93)\end{array}$ & $p$ & OR & $95 \% \mathrm{CI}$ \\
\hline $\mathrm{O}$ & $22(22,2)$ & $17(18,3)$ & 0,618 & 0,727 & $0,355-1,490$ \\
Non-O & $77(77,8)$ & $76(81,7)$ & & & \\
\hline
\end{tabular}

Data presented in $n(\%)$.

TABLE 4: Association of thrombomodulin gene polymorphism $-33 \mathrm{G}>\mathrm{A}$ with acute myocardial infarction.

\begin{tabular}{lccccc}
\hline Variables & $\begin{array}{c}\text { Case } \\
(n=99)\end{array}$ & $\begin{array}{c}\text { Control } \\
(n=93)\end{array}$ & $p$ & OR & $95 \% \mathrm{CI}$ \\
\hline GG & $91(91,9)$ & $83(89,2)$ & 0,699 & 1,37 & $0,516-3,637$ \\
AG/AA & $8(8,1)$ & $10(10,8)$ & & & \\
\hline
\end{tabular}

Data presented in $n$ (\%).

\section{Results}

The baseline characteristics of the sample (Table 2) showed that there were no significant differences in age, body height, and the presence of dyslipidemia. Significant difference between two groups was observed in body mass index, smoking status, and hypertension. The incidence of hypertension was significant in control group since most of the control group was obtained from hypertensive community patients.

Chi-square analysis of $\mathrm{ABO}$ polymorphism based on $\mathrm{O}$ and non-O blood group with the incidence of myocardial infarction showed that both blood groups had similar risk factor of myocardial infarction (Table 3). Furthermore, analysis between thrombomodulin $-33 \mathrm{G}>\mathrm{A}$ polymorphism and myocardial infarction suggested that carriers of GG genotype had similar risk factor of myocardial infarction compared to that of AG/AA genotype (Table 4). Moreover, analysis of the synergistic effect of both polymorphisms on myocardial infarction showed no significant difference. All groups showed no difference in myocardial infarction susceptibility compared to that of the reference gene (Table 5). 
TABLE 5: Synergistic association between thrombomodulin -33G>A gene polymorphisms and ABO gene polymorphism with the occurrence of acute myocardial infarct.

\begin{tabular}{|c|c|c|c|c|c|}
\hline Variables & Case $(n=99)$ & Control $(n=93)$ & $p$ & OR & $95 \% \mathrm{CI}$ \\
\hline GG/O & $22(22,2)$ & $14(15,1)$ & \multicolumn{3}{|c|}{ Reference gene } \\
\hline GG/non-O & $71(71,8)$ & $69(74,2)$ & 0,354 & 0,5 & $0,423-0,591$ \\
\hline AG/AA and non-O & $6(6)$ & $7(7,5)$ & 0,544 & 1,833 & $0,51-6,593$ \\
\hline AG/AA and $\mathrm{O}$ & $0(0)$ & $3(3,2)$ & 0,148 & 0,389 & $0,258-0,586$ \\
\hline
\end{tabular}

Data presented in $n(\%)$.

TABLE 6: Research summary of $\mathrm{ABO}$ gene polymorphisms on other populations.

\begin{tabular}{lccc}
\hline Author & Research subject & Sample number & OR (95\% CI) \\
\hline \multirow{2}{*}{ Wang et al. } & China subject & & 2365 \\
& AMI cases & 2768 & $1,03(0,8-1,33)$ \\
\hline Control & Southern China subject & 1716 & $1,279(0,713-2,452)$ \\
Huang et al. & AMI cases & 1572 & $1,857(1,112-3.1)$ \\
& Control & 250 & 250 \\
\hline
\end{tabular}

AMI: acute myocardial infarction and CAD: coronary acute disease.

\section{Discussion}

This study revealed different proportion of $\mathrm{ABO}$ phenotype compared to those of other populations. A study in Pakistan showed that the prevalence of blood group in ischemic heart disease was A 34\%, B 29\%, AB 14\%, and O 23\% [13]. This study showed the prevalence of blood group phenotype among myocardial infarction patients was A $54.5 \%$, B $21.2 \%$, O $22.2 \%$, and $\mathrm{AB} 2 \%$.

Some previous studies on Caucasians suggested the correlation of ABO polymorphism and myocardial infarction [1417]. This study categorized the sample based on $\mathrm{O}$ and non- $\mathrm{O}$ blood group. The result of this study is similar to previous study in China and South China (Table 6). Both studies used more than 2000 samples and identified some gene polymorphisms that became the risk factor of myocardial infarction in Caucasians in China population. Both studies revealed that $\mathrm{ABO}$ polymorphism that increases the susceptibility of myocardial infarction in Caucasian population failed to give significant result in China population [18, 19]. Ethnicity difference may contribute to the result of this study.

ABO polymorphism increases the susceptibility to myocardial infarction through some pathways, such as increasing vWF level, soluble intercellular adhesion molecule-1 level, soluble P-selectin level, and soluble E-selectin level [20]. However, the half-life of vWF and other cytokines was short (around 10 hours); therefore, we could not measure the vWF level. Moreover, ABO polymorphism affected circulated lipoprotein, triglyceride, and total cholesterol level [21]. This study revealed no significant difference in total cholesterol, triglyceride, $\mathrm{HDL}$, and LDL between $\mathrm{O}$ and non-O blood group. This fact might explain the result of this study.

ABO polymorphism cannot affect the myocardial infarction susceptibility solely. There must be another gene that synergistically increases the susceptibility. Thrombomodulin gene polymorphism was a polymorphism that is more commonly found in Asian population. However, some studies in other Asia regions suggested conflicting result (Table 7). A study in Korea revealed that carriers of -33G $>$ A thrombomodulin polymorphism had 4.63 times higher susceptibility to myocardial infarction [8]. Moreover, meta-analysis by Wang and Dong suggested that $-33 \mathrm{G}>\mathrm{A}$ polymorphism increases the susceptibility to coronary artery disease $(\mathrm{OR}=$ 1,65; 95\% CI, 1,35-2,02; $p<0,01 ; I^{2}=15 \%$ ) [22]. However, this study revealed no significant correlation between thrombomodulin polymorphism $-33 \mathrm{G}>\mathrm{A}$ and myocardial infarction. A study by Zhao et al. in 808 coronary artery disease patients and 813 healthy patients also failed to demonstrate a significant result [10]. Different genetic variation in different population might explain these different results.

\section{Conclusion}

This study showed that ABO polymorphism and thrombomodulin polymorphism $-33 \mathrm{G}>\mathrm{A}$ were not risk factors of AMI in Javanese males. 
TABLE 7: Research summary of thrombomodulin gene polymorphisms on other populations.

\begin{tabular}{|c|c|c|c|c|c|}
\hline \multirow{2}{*}{ Author } & \multirow{2}{*}{ Research subject } & \multicolumn{3}{|c|}{ Genotype } & \multirow{2}{*}{ OR $(95 \% \mathrm{CI})$} \\
\hline & & GG & AG/AA & Total & \\
\hline \multirow{3}{*}{ Park et al. } & Korean subject & & & & \\
\hline & AMI 1-VD & 18 & 12 & 30 & $4,36(1,62-13,31)$ \\
\hline & Control & 86 & 16 & 102 & \\
\hline \multirow{4}{*}{ Li et al. } & China and Taiwan subjec & & & & \\
\hline & AMI cases & 215 & 63 & 278 & $1,6(1,1-2,5)$ \\
\hline & Premature AMI cases & 51 & 21 & 72 & $2,3(1,3-4,1)$ \\
\hline & Control & 377 & 73 & 450 & \\
\hline \multirow{3}{*}{ Li et al. } & China and Taiwan subjec & & & & \\
\hline & CAD cases & 169 & 31 & 200 & $1,81(1,11-2,92)$ \\
\hline & Control & 244 & 76 & 320 & \\
\hline \multirow{5}{*}{ Zhao et al. } & China and North Han & & & & \\
\hline & AMI cases & 644 & 164 & 808 & $1,25(0,93-1,69)$ \\
\hline & CAD cases & 398 & 107 & 505 & $1,23(0,88-1,73)$ \\
\hline & Premature AMI & 146 & 42 & 146 & $1,45(0,87-2,44)$ \\
\hline & Control & 662 & 151 & 813 & \\
\hline \multirow{4}{*}{ Dogra et al. } & North Indian & & & & \\
\hline & subject & & & & \\
\hline & AMI cases & 182 & 7 & 189 & $0,5(0,1-2,6)$ \\
\hline & Control & 343 & 2 & 345 & \\
\hline
\end{tabular}

1-VD: one vessel disease; AMI: acute myocardial infarction; CAD: coronary acute disease.

\section{Conflicts of Interest}

The authors declare that they have no conflicts of interest.

\section{References}

[1] S. Yusuf, S. Reddy, S. Ôunpuu, and S. Anand, "Global burden of cardiovascular diseases. Part I: general considerations, the epidemiologic transition, risk factors, and impact of urbanization," Circulation, vol. 104, no. 22, pp. 2746-2753, 2001.

[2] J. C. Souto, L. Almasy, E. Muñiz-Diaz et al., "Functional effects of the ABO locus polymorphism on plasma levels of von Willebrand factor, factor VIII, and activated partial thromboplastin time," Arteriosclerosis, Thrombosis, and Vascular Biology, vol. 20, no. 8, pp. 2024-2028, 2000.

[3] M. E. Marenberg, N. Risch, L. F. Berkman, B. Floderus, and U. De Faire, "Genetic susceptibility to death from coronary heart disease in a study of twins," The New England Journal of Medicine, vol. 330, no. 15, pp. 1041-1046, 1994.

[4] K. L. Wiggins, N. L. Smith, N. L. Glazer et al., "ABO genotype and risk of thrombotic events and hemorrhagic stroke," Journal of Thrombosis and Haemostasis, vol. 7, no. 2, pp. 263-269, 2009.

[5] P. V. Jenkins and J. S. O'Donnell, "ABO blood group determines plasma von Willebrand factor levels: a biologic function after all?” Transfusion, vol. 46, no. 10, pp. 1836-1844, 2006.

[6] J. O'Donnell and M. A. Laffan, “The relationship between ABO histo-blood group, factor VIII and von Willebrand factor," Transfusion Medicine, vol. 11, no. 4, pp. 343-351, 2001.

[7] Y.-H. Li, J.-H. Chen, H.-L. Wu et al., "G-33A mutation in the promoter region of thrombomodulin gene and its association with coronary artery disease and plasma soluble thrombomodulin levels," American Journal of Cardiology, vol. 85, no. 1, pp. $8-12,2000$.
[8] H.-Y. Park, T. Nabika, Y. Jang, H. M. Kwon, S. Y. Cho, and J. Masuda, "Association of G-33A polymorphism in the thrombomodulin gene with myocardial infarction in Koreans," Hypertension Research, vol. 25, no. 3, pp. 389-394, 2002.

[9] Y. Yamada, H. Izawa, S. Ichihara et al., "Prediction of the risk of myocardial infarction from polymorphisms in candidate genes," The New England Journal of Medicine, vol. 347, no. 24, pp. 1916-1923, 2002.

[10] J. Zhao, X. Zhou, J. Huang, J. Chen, and D. Gu, "Association study of the thrombomodulin -33Ggt;A polymorphism with coronary artery disease and myocardial infarction in Chinese Han population," International Journal of Cardiology, vol. 100, pp. 383-388, 2005.

[11] Y.-H. Li, J.-H. Chen, W.-C. Tsai et al., "Synergistic effect of thrombomodulin promoter -33G/A polymorphism and smoking on the onset of acute myocardial infarction," Thromb. Haemost, vol. 87, pp. 86-91, 2002.

[12] S. Al-Bustan, M. El-Zawahri, D. Al-Azmi, and A.-A. Al-Bashir, "Allele frequencies and molecular genotyping of the ABO blood group system in a Kuwaiti population," International Journal of Hematology, vol. 75, no. 2, pp. 147-153, 2002.

[13] S. Sharif, N. Anwar, T. Farasat, and S. Naz, "ABO blood group frequency in ischemic heart disease patients in Pakistani population," Pakistan Journal of Medical Sciences, vol. 30, no. 3, pp. 593-595, 2014.

[14] F. Biancari, J. Satta, R. Pokela, and T. Juvonen, "ABO blood group distribution and severity of coronary artery disease among patients undergoing coronary artery bypass surgery in Northern Finland," Thrombosis Research, vol. 108, no. 2-3, pp. 195-196, 2002.

[15] M. He, B. Wolpin, K. Rexrode et al., "ABO blood group and risk of coronary heart disease in two prospective cohort studies," 
Arteriosclerosis, Thrombosis, and Vascular Biology, vol. 32, no. 9, pp. 2314-2320, 2012.

[16] I. Jukic, J. Bingulac-Popovic, V. Dogic et al., "Evaluation of ABO blood groups as a risk factor for myocardial infarction," Blood Transfusion, vol. 11, no. 3, pp. 464-465, 2013.

[17] A. Miñano, A. Ordóñez, F. España et al., "AB0 blood group and risk of venous or arterial thrombosis in carriers of factor V Leiden or prothrombin G20210A polymorphisms," Haematologica, vol. 93, no. 5, pp. 729-734, 2008.

[18] E.-W. Huang, L.-Y. Peng, J.-X. Zheng et al., "Investigation of associations between ten polymorphisms and the risk of coronary artery disease in Southern Han Chinese," Journal of Human Genetics, vol. 61, no. 5, pp. 389-393, 2016.

[19] Y. Wang, L. Wang, X. Liu et al., "Genetic variants associated with myocardial infarction and the risk factors in Chinese population," PLoS ONE, vol. 9, no. 1, Article ID e86332, 2014.

[20] S. Kiechl, G. Paré, M. Barbalic et al., "Association of variation at the ABO Locus with circulating levels of soluble intercellular adhesion molecule-1, Soluble P-selectin, and Soluble E-selectin: a meta-analysis," Circulation: Cardiovascular Genetics, vol. 4, no. 6, pp. 681-686, 2011.

[21] Y. Chen, C. Chen, X. Ke et al., "Analysis of circulating cholesterol levels as a mediator of an association between ABO blood group and coronary heart disease," Circulation: Cardiovascular Genetics, vol. 7, no. 1, pp. 43-48, 2014.

[22] H. Wang and P. Dong, "Thrombomodulin - 33G/A and Ala455Val polymorphisms are associated with the risk of coronary artery disease: a meta-analysis including 12584 patients," Coronary Artery Disease, vol. 26, no. 1, pp. 72-77, 2015. 


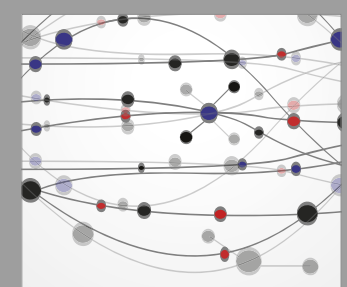

The Scientific World Journal
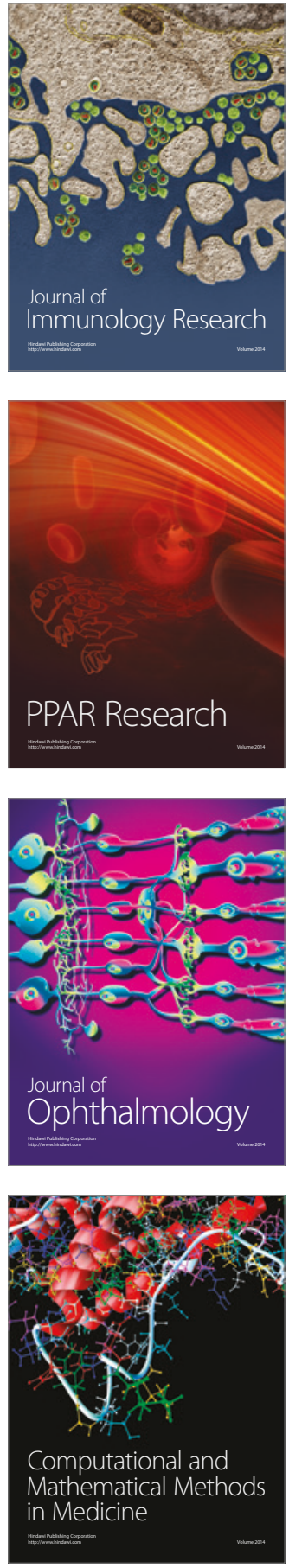

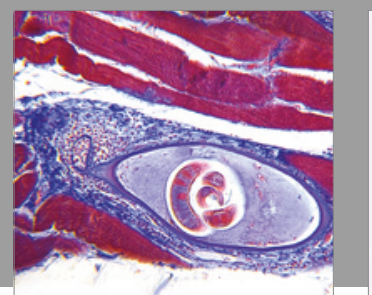

Gastroenterology Research and Practice
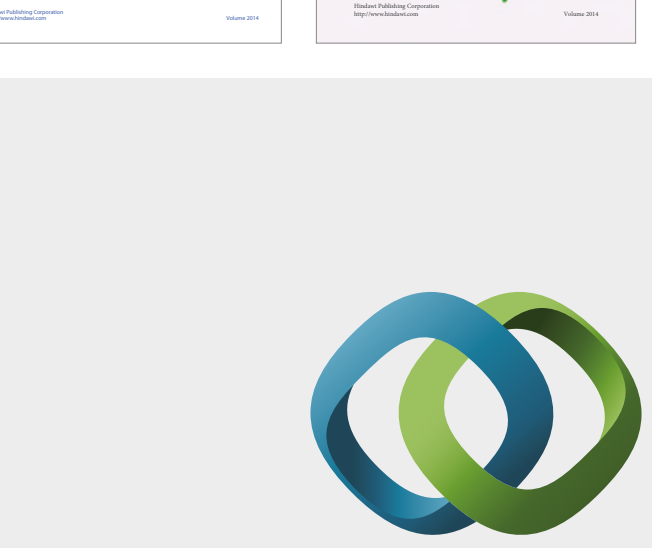

\section{Hindawi}

Submit your manuscripts at

https://www.hindawi.com
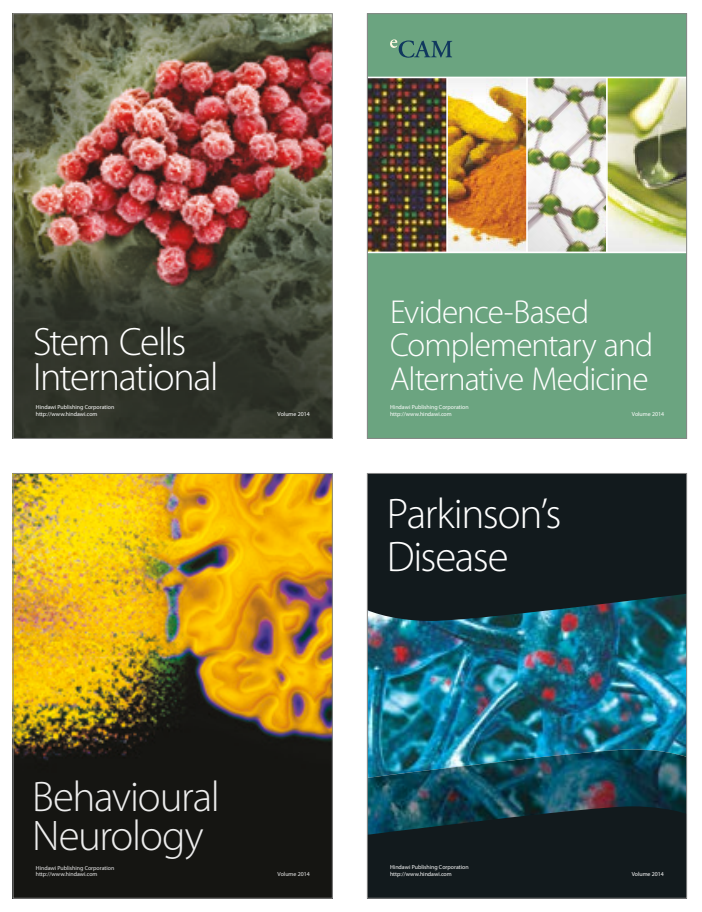
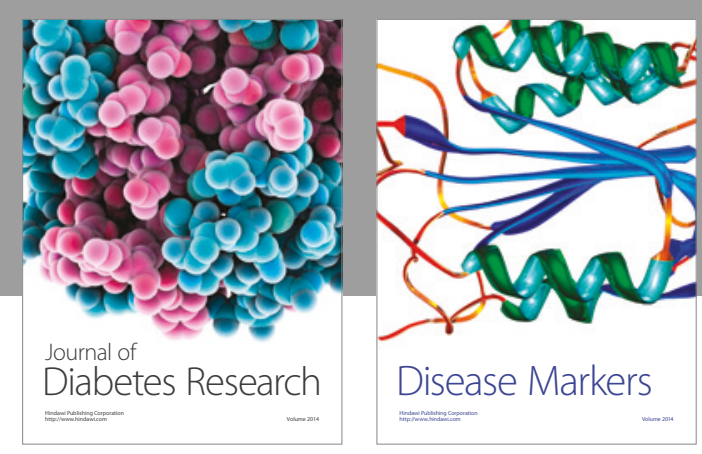

Disease Markers
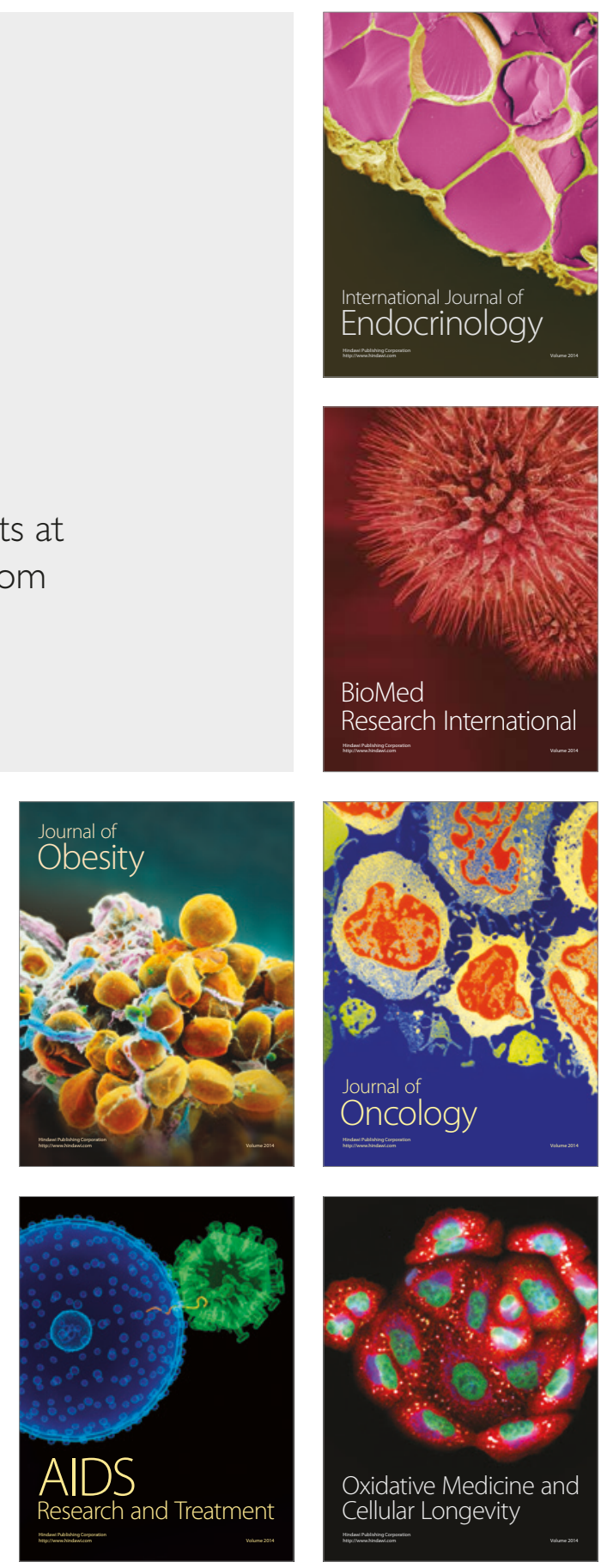